\title{
The Medicago truncatula MtAnn1 Gene Encoding an Annexin Is Induced by Nod Factors and During the Symbiotic Interaction with Rhizobium meliloti
}

\author{
Fernanda de Carvalho Niebel, Nicole Lescure, Julie V. Cullimore, and Pascal Gamas \\ Laboratoire de Biologie Moléculaire des Relations Plantes-Microorganismes, INRA-CNRS, UMR 215, BP \\ 27, 31326 Castanet-Tolosan Cedex, France \\ Accepted 16 February 1998.
}

\begin{abstract}
Here we report the characterization of a new Nod factorinduced gene from Medicago truncatula identified by mRNA differential display. This gene, designated MtAnn1, encodes a protein homologous to the annexin family of calcium- and phospholipid-binding proteins. We further show that the MtAnn1 gene is also induced during symbiotic associations with Rhizobium meliloti, both at early stages in bacterial-inoculated roots and in nodule structures. By in situ hybridization, we demonstrate that MtAnn1 expression in nodules is mainly associated with the distal region of invasion zone II not containing infection threads, revealing MtAnn1 as a new marker gene of the pre-infection zone. Moreover, analyses of MtAnn1 expression in response to bacterial symbiotic mutants suggest that the expression of MtAnn1 during nodulation requires biologically active Nod factors and is independent of the infection process.
\end{abstract}

Additional keywords: supernodulating mutant line, symbiosis.

The symbiotic association between leguminous plants and rhizobia (Azorhizobium, Bradyrhizobium, and Rhizobium) culminates in the formation of a new root organ known as the nodule, in which the bacteria reside and convert atmospheric nitrogen into ammonium, which is then assimilated by the host plant. Nodule development in temperate legumes such as Medicago spp. is initiated by the specific attachment of Rhizobium bacteria to plant root hairs leading to hair deformation (Had) and curling (Hac), morphological changes characteristic of the symbiotic stage preceding bacterial infection. Within the curled root hairs, the invading bacteria induce the formation of new tubular structures, the infection threads (ITs), within which Rhizobium bacteria progress toward the inner root cortical cells. Concomitantly, these inner cortical cells divide, resulting in the formation of a nodule primordium. Once the ITs reach the primordium, bacteria are released into the plant cells and an apical meristem is formed. Subsequent growth and differentiation results in the development of the nodule structure of indeterminate type, composed of a persis-

Corresponding author: Fernanda de Carvalho Niebel; Telephone: (33) 561285 322; Fax: (33) 561285 061; E-mail: fniebel@ toulouse.inra.fr

Nucleotide and/or amino acid sequence data are to be found at the EMBL data base as accession number Y15036. tent apical meristem (zone I) followed by different zones corresponding to distinct developmental stages of bacterial and plant differentiation. In a mature nodule structure, the meristematic zone I is followed successively by invasion zone II (where infection of the plant cells takes place), the amyloplast-rich interzone II-III, the fixation zone III (where $R$. meliloti differentiates into bacteroids that fix nitrogen) and the senescence zone IV (where bacteria cells degenerate) (for review see Mylona et al. 1995).

The initiation and development of the nodulation process require bacterial-secreted lipochitooligosaccharide signal molecules, called Nod factors (reviewed in Dénarié et al. 1996). Nod factors produced by various rhizobia are composed of a backbone of four or five $\beta$-1,4-linked glucosamine residues, $\mathrm{N}$-acylated on the nonreducing sugar and $\mathrm{N}$ acetylated on the other residues. Further modifications on the reducing and nonreducing sugars of the Nod factors are specific for each rhizobia species and can be important determinants of host specificity. For example, $R$. meliloti bacteria that nodulate plants of Medicago spp. produce mainly tetrameric Nod factors decorated by a sulfate group on the reducing sugar and an $O$-acetate and a C16:2 acyl chain on the nonreducing sugar (reviewed by Dénarié et al. 1996). Purified Nod factors can induce early symbiotic responses in the roots of host plants, and in some plant species they can also induce the formation of nodule structures (reviewed by Dénarié et al. 1996; Heidstra and Bisseling 1996; Long 1996; Schultze and Kondorosi 1996; Spaink 1996). Examples of early responses induced by Nod factors include membrane depolarization, increased cytoplasmic $\mathrm{pH}$, calcium spiking, and Had, in epidermal cells; the activation and division of root cortical cells; and the induction of specific plant gene expression, in epidermal, cortical, and pericycle tissues.

Plant genes that are expressed during the nodulation process are referred to as nodulin genes and are classified as early or late, according to their timing of expression during the nodulation process (for review see Mylona et al. 1995; Heidstra and Bisseling 1996). Late nodulin genes are mainly expressed in mature nodule structures around the onset of nitrogen fixation. Early nodulin genes are generally expressed during the early stages of nodulation and are thus believed to be involved in the infection process and/or nodule organogenesis. Although nodulin genes were initially considered to be specifically expressed during symbiotic associations with rhizobia, 
many of them are likely to participate in other plant developmental processes, since they are also expressed in other plant tissues (see for example Crespi et al. 1994; Matvienko et al. 1994; Cook et al. 1995; Bauer et al. 1996; Papadopoulou et al. 1996).

Studies on early nodulin gene expression have revealed these genes to be valuable molecular markers for studying early stages of the symbiotic process. Several of these genes are induced by purified Nod factors and hence are also useful markers for studies of Nod-factor-induced plant responses (Horvath et al. 1993; Journet et al. 1994; Vijn et al. 1995; Minami et al. 1996). Although homologies to known gene products have been found for a number of early nodulin genes (Cook et al. 1995; Goormachtig et al. 1995; Bauchrowitz et al. 1996; Gamas et al. 1996; Coba de la Pena et al. 1997; Heidstra et al. 1997), the function of specific gene products in the symbiotic process remains to be determined.

We are studying the symbiotic interaction between the legume Medicago truncatula and the bacterial symbiont Rhizobium meliloti. To extend our knowledge concerning the initiation and development of the nodule organogenesis program in $M$. truncatula, we decided to isolate new plant genes induced during the early stages of symbiosis. To this end we used the differential display approach to identify Nod-factor-induced genes likely to be associated with these early symbiotic stages.

Here we report the characterization of one of the Nodfactor-induced cDNA clones coding for a putative calciumand phospholipid-binding annexin protein. We have demonstrated that the new gene, named MtAnnl for Medicago truncatula Annexin $\underline{1}$, corresponds to a new early nodulin gene expressed both at early stages of the symbiotic process and also at the distal end of the early symbiotic zone II of nodules. Additionally, our results indicate that MtAnnl expression during symbiosis requires biologically active Nod factors and is independent of the infection process.

\section{RESULTS}

\section{Identification by differential display}

\section{of a new Nod-factor-induced $M$. truncatula gene.}

To identify new $M$. truncatula genes induced by purified $R$. meliloti Nod factors (NodRm factors), we used the sensitive polymerase chain reaction (PCR)-based technique of differential display (Liang et al. 1994). With this method, differentially expressed mRNAs are detected in different RNA samples by comparing the patterns of partial cDNAs generated after reverse transcription and PCR amplification with arbitrary primers. This strategy therefore has the advantage of allowing the detection of relatively low-abundant mRNA species.

We have compared gene expression patterns with RNAs isolated from $M$. truncatula roots after treatment either with $10^{-7} \mathrm{M}$ NodRm factors or with the growth medium only (controls). These RNA samples were used to synthesize firststrand cDNAs with anchored oligo dT 3 ' primers, which were subsequently amplified by PCR with the same oligo dT $3{ }^{\prime}$ primer and arbitrary 10 -mer $5^{\prime}$ primers (see Materials and Methods). The cDNA subpopulations from NodRm-treated and control samples obtained in this way were compared on polyacrylamide gels, where differential bands could be identi- fied and isolated. We first analyzed samples that were harvested 2 and $24 \mathrm{~h}$ after NodRm or growth medium treatments. No differential bands were identified for these samples although a relatively large number of RNA species were analyzed (about 4,000 and 2,400, respectively). To increase the chances of finding Nod-factor-induced genes, we decided to use root samples that had been nitrogen-starved for a longer period (10 days, instead of 6 days as for the previous samples) and treated for a longer time $(48 \mathrm{~h})$ with NodRm factors. Four cDNA bands showing enhanced amplification in the 48-h NodRm-treated samples were identified with fewer primer combinations (20) than the previous experiments (51 and 31). After excision from the gels, re-amplification, and cloning, the four clones, named $d d A, d d B, d d C$, and $d d D$ of, respectively, 373,295 , 402, and $284 \mathrm{bp}$, were used as probes on RNA gel blots to verify the induction by Nod factors. This was confirmed for $d d A$ and $d d B$, although hybridizing signals were weak (data not shown), while the expression of $d d C$ and $d d D$ was undetectable following RNA gel blot analysis.

This paper focuses on the characterization of the differential display clone $d d A$, represented in Figure 1A, for which a fulllength cDNA clone was isolated to improve the sensitivity of the expression analysis. DNA gel blot analysis at high stringency conditions with the entire $d d A$ cDNA as a probe revealed one major hybridizing band, suggesting that $d d A$ is a single-copy gene in $M$. truncatula (data not shown). To better evaluate the Nod factor induction of $d d A$, RNA gel blot analysis was carried out with total RNA from $M$. truncatula roots treated for different times with $10^{-7} \mathrm{M}$ NodRm. As shown in Figure 1B, increased levels of $d d A$ transcripts were clearly detected in M. truncatula roots treated for $48 \mathrm{~h}$ with NodRm factors. A similar induction was also detected on NodRmtreated roots of another $M$. truncatula genotype, the supernodulating mutant TR122 (Sagan et al. 1995) (see Materials and Methods) (Fig. 1B). RNA gel blot analysis of Nod-factor induction of $d d A$ expression at earlier time points $(3,6,12$, and $24 \mathrm{~h}$ ) was not conclusive due to the variation in the basal levels of $d d A$ expression observed in control roots (data not shown).

\section{The Nod-factor-induced M. truncatula MtAnn1 gene encodes an annexin-like protein.}

The $d d A$ cDNA clone is 1,202 bp long with 216 bp of untranslated sequence preceding the polyA tail. The transcript and the cDNA insert size of about $1.2 \mathrm{~kb}$ is consistent with the $d d A$ cDNA clone being about full length. Sequence analysis of the $d d A$ cDNA revealed a single open reading frame encoding a protein of 313 amino acids with a predicted molecular mass of $35.6 \mathrm{kDa}$ and an isoelectric point of 7.8. The PSORT program (version 6.4; Nakai and Kanehisa 1992) predicts the $d d A$ encoded protein to be cytoplasmic (with a confidence of 0.65 ). Data base searches revealed that the putative encoded protein shows homology to the annexin family of calcium- and phospholipid-binding proteins, with the highest homologies to plant annexin sequences, as shown in Table 1. The $d d A$ clone was then designated MtAnnl, for Medicago truncatula $\underline{A n-}$ nexin $\underline{1}$.

Annexins have been described in many eukaryotic organisms, including animals, plants, and protists. Annexins proteins are composed of a variable $\mathrm{N}$-terminal region and a highly conserved $\mathrm{C}$-terminal core formed by four (and some- 
times eight) repeats of about 70 amino acids that are also found in the MtAnnl sequence, as indicated in Figure 2. Within the repeats, we find a 17-amino-acid consensus sequence or the "endonexin fold" that is generally highly conserved in repeats 1, 2, and 4 of animal sequences (Fig. 2). In

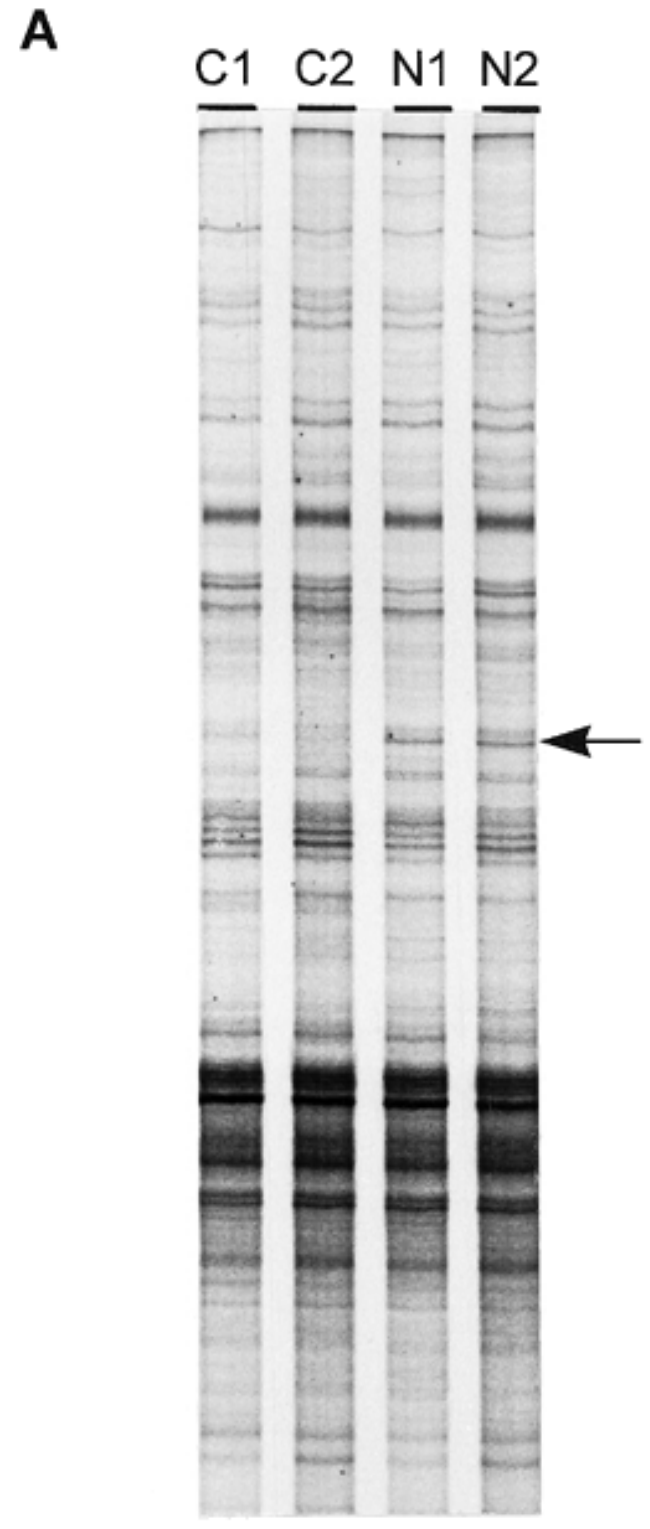

\section{B}

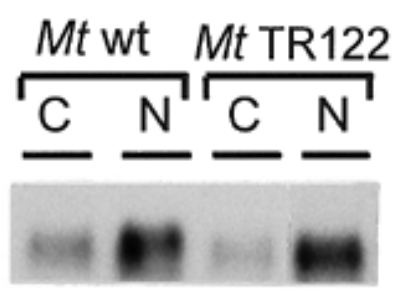

MtAnn1

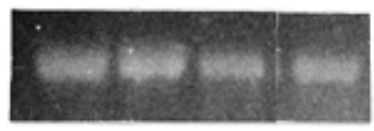

the MtAnnl sequence, the "endonexin fold" region is highly conserved in repeats 1 and 4 (93 and $80 \%$ similarity to consensus sequence, respectively, with the blosum 62 amino acid matrix with a score +1 or higher), and sequence conservation decreases successively in repeat $3(67 \%)$ and repeat $2(47 \%)$. The major sites for calcium binding defined as type II are characterized by a discontinuous sequence corresponding to G-X-G-T-( $\left.\mathrm{X}_{38}\right)-(\mathrm{D}, \mathrm{E})$ where $\mathrm{X}$ is any residue (for reviews see Raynal and Pollard 1994; Clark and Roux 1995). The entire type II calcium-binding site is only conserved in repeat 1 of MtAnn1. However, the glutamic acid (E) or the aspartic acid (D) residues located in the C-terminal position within the conserved motif are also conserved in repeats 3 and 4 of the plant sequences (Fig. 2).

\section{The Nod-factor-induced MtAnn1 gene is also expressed during symbiotic interactions with $\boldsymbol{R}$. meliloti.}

To evaluate whether the induction of MtAnn1 expression by NodRm factors is related to the nodulation process, MtAnnl mRNA levels were examined in $M$. truncatula roots at different times following inoculation with $R$. meliloti. In our experimental conditions nodules can be initially visualized as small bumps 3 to 4 days post-inoculation. As shown in Figure 3A, induction of MtAnnl expression is detected at different stages of nodulation, in inoculated roots $(48 \mathrm{~h})$ and in roots containing both young (4-day-old) and mature (16-day-old) nodule structures. Subsequent analysis revealed that substantial levels of MtAnnl mRNA are found in both young and mature isolated nodules (Fig. 3A). MtAnnl mRNA levels detected in roots that were inoculated with a non-nodulating (nod $A)$ mutant of $R$. meliloti, which does not produce Nod factors, were generally close to the basal levels of MtAnnl expression.

To further characterize MtAnnl expression at early stages of the nodulation process, RNA gel blot analysis was carried out with poly $\mathrm{A}^{+}$RNA isolated from roots harvested 3,24 , and 48 $\mathrm{h}$ after inoculation with either wild-type $R$. meliloti or the nod $A$ mutant as a negative control. As shown in Figure 3B, high levels of MtAnnl mRNA were readily detected $24 \mathrm{~h}$ after root inoculation with wild-type $R$. meliloti. No induction was detected for MtAnnl $3 \mathrm{~h}$ after inoculation, although we cannot exclude that low level induction may be masked by the basal level of expression in roots.

To examine whether MtAnnl is expressed in other tissues of the plant, RNAs from flowers, stems, and leaves were analyzed by RNA gel blots. As shown in Figure 3C, MtAnn1

Fig. 1. Induction of the Medicago truncatula annexin gene MtAnnl by Rhizobium Nod factors. A, Area of the differential display gel showing the NodRm-enhanced polymerase chain reaction (PCR) band corresponding to the MtAnnl annexin gene. Two independent reverse transcription (RT)-PCR reactions of RNA from control (C1 and $\mathrm{C} 2$ ) and NodRm-treated (N1 and N2) roots were resolved on a $6 \%$ denaturing polyacrylamide gel. Arrow indicates the 373-base $d d A$ PCR fragment. B, RNA gel blot analysis of Nod factor-treated roots. Ten micrograms of total RNA from roots of wild type $(M t w t)$ and from the supernodulating TR122 line (Mt TR122) of $M$. truncatula were loaded in each lane. Roots were treated for $48 \mathrm{~h}$ with growth medium only (C) or growth medium plus 10-7 M NodRm factors (N). Blots were hybridized with ${ }^{32} \mathrm{P}$-labeled, full-length $d d A$ riboprobes. Ethidium bromide-stained $28 \mathrm{~S}$ rRNA on the blotted membrane reveals the uniformity of RNA loading. 
mRNA was barely detectable in flower tissues, and undetectable in leaves and stems. MtAnnl expression was also examined in leaves in response to different stress conditions such as wounding and infection by the respective incompatible and compatible pathogenic bacteria Pseudomonas syringae pv. pisi and Xanthomonas campestris pv. alfalfae. No induction of MtAnnl expression was observed under conditions in which the stress-related genes chalcone synthase and the $M$. truncatula pathogenesis-related PR-10 gene (MtPR10-1) (Gamas et al. 1998) were strongly induced (data not shown).
To better understand the specificity of MtAnnl expression in relation to the symbiotic process, RNA gel blot analysis was performed with RNA extracted from $M$. truncatula roots inoculated with various symbiotic mutants unable to produce genuine nodule structures. The bacterial mutants tested were: nodH (producing Nod factors lacking the host specificity determinant sulfate group on the reducing sugar), nodFL (producing Nod factors modified on the non-reducing sugar, lacking the $O$-acetyl group and with a C18:1 instead of a C16:2 acyl chain), and exoA (deficient in a surface acidic polysaccharide). In M. truncatula plants, nodH R. meliloti (as

Table 1. Comparison of MtAnn1 with other annexin sequences

\begin{tabular}{|c|c|c|c|c|c|}
\hline \multirow[b]{2}{*}{ Annexin sequences ${ }^{a}$} & \multirow{2}{*}{$\begin{array}{c}\text { BLASTX } \\
{\text { (probability })^{\mathbf{b}}}^{\mathbf{b}}\end{array}$} & \multicolumn{3}{|c|}{ BESTFIT $^{c}$} & \multirow[b]{2}{*}{ Accession nos. } \\
\hline & & $\% \mathrm{~S}$ & $\%$ I & AA no. & \\
\hline Strawberry cDNA clone (FaAnn) & $1.1 \mathrm{e}-126$ & 79.1 & 69.4 & 268 & U19941 \\
\hline Maize annexin p33 cDNA clone (ZmAnnp33) & $9.7 \mathrm{e}-103$ & 62.5 & 52.2 & 312 & X98244 \\
\hline Arabidopsis thaliana cDNA clone (AtAnn) & $1.1 \mathrm{e}-102$ & 59.4 & 49.5 & 313 & $\mathrm{U} 28415$ \\
\hline Alfalfa cDNA clone (MsAnn) & $1.4 \mathrm{e}-102$ & 61.4 & 51.5 & 303 & X74947 \\
\hline Maize annexin p35 cDNA clone (ZmAnnp35) & $1.1 \mathrm{e}-100$ & 61.2 & 52.6 & 312 & X98245 \\
\hline Cotton cDNA clone (GhAnn) & $1.6 \mathrm{e}-100$ & 62.7 & 54.0 & 300 & U73747 \\
\hline Bell pepper cDNA clone (CaAnn) & $1.0 \mathrm{e}-98$ & 59.2 & 50.8 & 313 & X93308 \\
\hline Chicken Annexin V (GgAnnV) & $6.3 e-56$ & 46.0 & 35.7 & 311 & P17153 \\
\hline Human Annexin XIII (HsAnnXIII) & $1.4 \mathrm{e}-54$ & 46.4 & 34.4 & 308 & $\mathrm{P} 27216$ \\
\hline
\end{tabular}

a The indicated sequences correspond to the nine best homologies found with the BLASTX program, using the nonredundant protein data base (Altschul et al. 1990).

b The probability of finding these homologies by chance.

${ }^{c}$ Percentage of sequence similarities (\% S) and identities (\% I) at the amino acid level found with the BESTFIT GCG program. AA no. corresponds to the number of amino acid residues for which homologies were found.

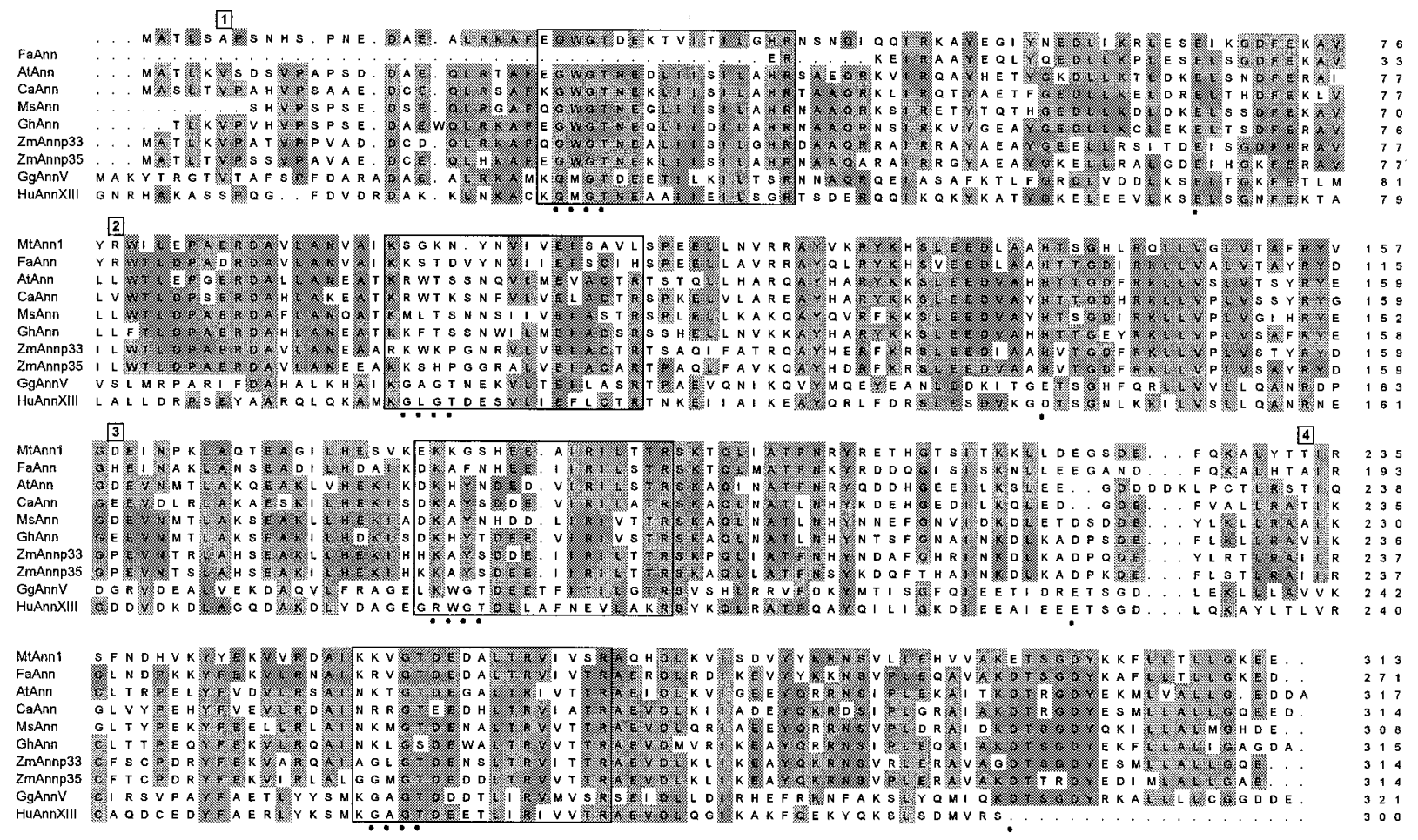

Fig. 2. Amino acid sequence alignment of MtAnn1 to other annexin sequences. MtAnn1 is aligned with the deduced amino acid sequences of plant (FaAnn, AtAnn, CaAnn, MsAnn, GhAnn, ZmAnnp33, and ZmAnnp35) and animal (GgAnnV and HuAnnXIII) annexins. Annexin sequence abbreviations are defined in Table 1. Numbers 1 to 4 above the MtAnn1 sequence refer to the start of the characteristic annexin repeat domains according to Raynall and Pollard (1994). Boxed areas correspond to the 17 amino acid-endonexin fold region with its characteristic KGhGTDEXXLIpILApR motif (h $=$ hydrophobic residue; $\mathrm{X}=$ any residue; $\mathrm{p}=$ polar residue). Black dots below the HuAnnXIII sequence indicate expected position of the four first and last residues within the consensus type II calcium-binding site defined as G-X-G-T-(X38)-(D/E), where X can be any residue. Alignment was obtained with the CLUSTAL W 1.7 program (blosum matrix; Thompson et al. 1994). Identical residues for at least six of the 10 sequences are shaded. 
nodA) is non-nodulating, and does not elicit any of the early morphological symbiotic responses. The nodFL mutant is neither able to infect the plant roots nor to elicit nodules but is still able to induce some of the primary symbiotic responses such as root hair deformation and cortical cell activation (Ardourel et al. 1994). Finally, exoA bacteria are blocked during the infection process but can still induce the formation of bacteria-free nodule structures (Yang et al. 1992). In a number of independent experiments, the induction of MtAnnl expression was only clearly observed in exoA-inoculated roots (data not shown). In order to improve sensitivity we chose to use a supernodulating mutant line of Medicago truncatula, TR122 (Sagan et al. 1995), characterized by an enhanced number of nodules formed throughout the root system. MtAnnl expression levels were higher in TR122 than in wild-type M. truncatula $R$. meliloti-inoculated roots (not shown). As shown in Figure 3D,

A

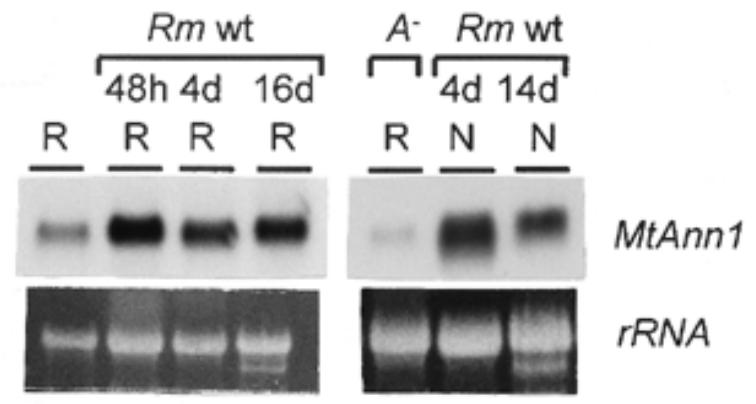

B

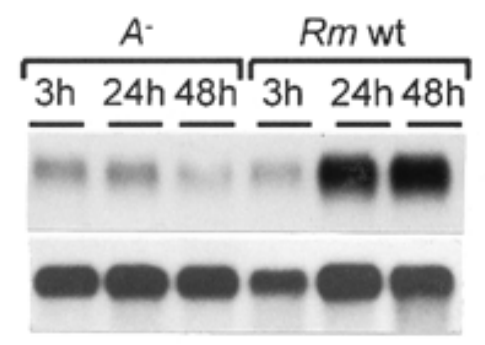

MtAnn1

$E F-/ \propto$

C

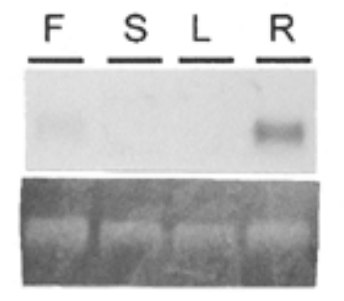

MtAnn1

rRNA

D

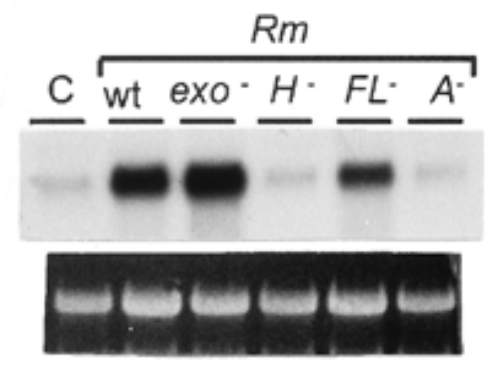

MtAnnl expression was clearly induced by exoA and nodFL bacterial mutants in TR122-inoculated roots. As expected, no significant induction of MtAnnl expression was observed in response to the bacterial mutants $\operatorname{nod} A$ and $\operatorname{nodH}$.

\section{MtAnn1 mRNA is localized to distal zone II of $M$. truncatula nodules.}

To determine the tissue specificity of MtAnnl expression during nodule development, in situ hybridizations were carried out on sections of $M$. truncatula nodules harvested at different times following inoculation with $R$. meliloti bacteria.

MtAnn1 expression was first analyzed in wild-type $R$. meliloti-induced nodules of $M$. truncatula. At a relatively early stage of nodule development ( 6 days after inoculation), as shown in Figure 4A and $4 \mathrm{~B}$, an apical meristematic region followed by a central region with ramifying infection threads penetrating the plant cells is observed. MtAnn1 transcripts were exclusively detected within central tissues, but with the highest hybridization signal associated with the more distal part of this region, adjacent to the meristematic cells (Fig. 4B). At higher magnifications, it can be seen that the highest density of silver grains is localized to the region where infection threads are not yet present (Fig. 4D and E). A control nodule section hybridized with sense MtAnnl probes is shown in Figure 4C. As shown in Figure $4 \mathrm{~F}$ and $\mathrm{G}$, a similar but more restricted hybridization pattern is observed in more mature nodules (18 days post-inoculation), where MtAnnl transcripts were mainly localized to the distal part of invasion zone II adjacent to the meristem and lacking infection threads, a region that has been termed the pre-infection zone (Pichon et al. 1992). The more localized expression of MtAnnl in mature nodules correlates with a more clearly defined zone II, indicating that MtAnnl transcripts are associated with the same region throughout nodule development. Signals were detected neither in the proximal region of zone II nor in zone III, containing bacteria-infected plant cells. Furthermore, signals were found neither in the peripheral nodule tissues nor in root tissues surrounding the nodule structures.

Fig. 3. MtAnnl expression analysis by gel blots. A, Induction of MtAnnl expression in Rhizobium meliloti-inoculated roots $(\mathrm{R})$ and nodules $(\mathrm{N})$. Total RNA isolated from $M$. truncatula roots before (R) and $48 \mathrm{~h}(48 \mathrm{~h})$, 4 days (4d) or 16 days (16d) after inoculation with $R$. meliloti $(R m \mathrm{wt})$; RNA from $M$. truncatula roots 4 days after inoculation with the nonnodulating Rhizobium mutant nodA $\left(A^{-}, \mathrm{R}\right)$ and RNA from young, 4day-old $(R m \mathrm{wt}, 4 \mathrm{~d} \mathrm{~N})$ and mature, 14-day-old $(R m \mathrm{wt}, 14 \mathrm{~d} \mathrm{~N})$, isolated $R$. meliloti-induced nodules. B, Early induction of $M t A n n 1$ expression in $R$. meliloti-inoculated roots. Poly A+ RNA from entire roots harvested at different times $(3,24$, and $48 \mathrm{~h})$ after inoculation with nodA mutant $\left(A^{-}\right)$ or wild-type ( $R m$ wt) $R$. meliloti. C, Analysis of MtAnnl expression in different plant tissues. Total RNA isolated from flowers (F), stems (S), leaves (L), and roots (R) of $M$. truncatula. D, Differential induction of MtAnn1 by $R$. meliloti symbiotic mutants. Total RNA extracted from entire roots of $M$. truncatula TR122 plants 6 days after inoculation with R. meliloti $(\mathrm{Rm})$ wild type (wt) and mutants exoA $\left(\right.$ exo $\left.^{-}\right)$, nodH $\left(H^{-}\right)$, $\operatorname{nod} F L\left(F L^{-}\right)$, and nodA $\left(A^{-}\right)$. Control RNA sample $(\mathrm{C})$ was isolated from roots of plants 6 days after treatment with growth medium only. For A, $\mathbf{C}$, and $\mathbf{D}, 10 \mu \mathrm{g}$ of total RNA was loaded per lane, and ethidium bromide-stained 28S rRNA on the blotted membrane is shown below. For B, approximately $120 \mathrm{ng}$ of poly A+ RNA was loaded per lane, and RNA loading was controlled by hybridizing blots to a DNA probe to detect translation elongation factor EF- $1 \alpha$ transcripts. Riboprobes were used to detect MtAnnl transcripts. 
MtAnnl expression was also examined during nodule development in $M$. truncatula TR122 plants. Because of the supernodulation phenotype we were able to analyze, in the same section, nodules of different developmental stages. In sections of TR122 roots 6 days post-inoculation, certain nodules were at a similar developmental stage as wild-type $M$. truncatula nodules of the same age (Fig. $4 \mathrm{H}$, upper part) but younger stages of nodule development were also observed (Fig. 4H, bottom). MtAnn1 hybridization signals in immature TR122 nodules were located in the same region as in wild-type nodules of the same age (compare Figure 4B and $\mathrm{H}$ ), demonstrating that the pattern of MtAnnl expression seen in wildtype nodules is conserved in TR122 nodules. Earlier developmental stages revealed in sections of TR122-nodulated
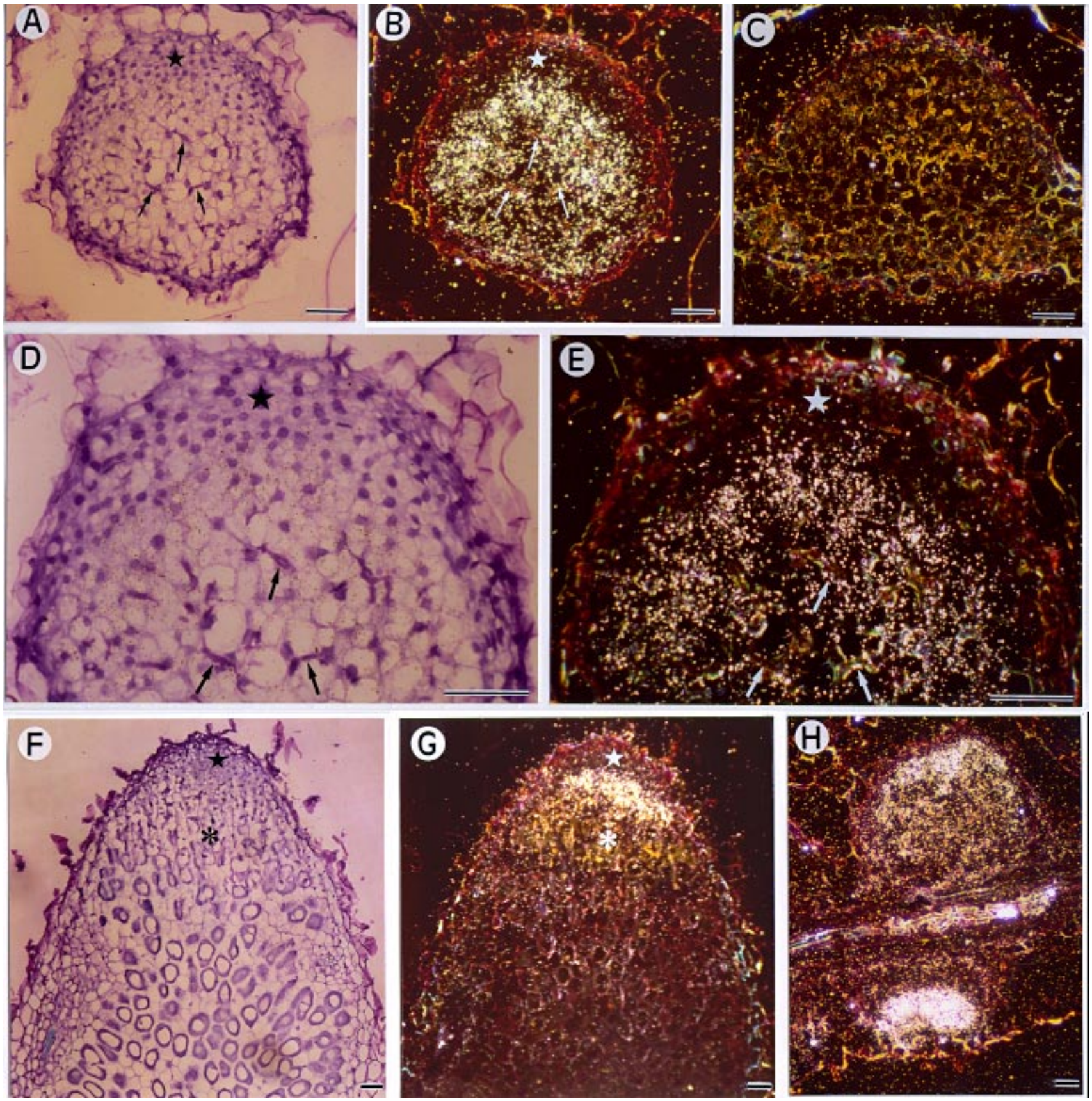

Fig. 4. Cell-specific localization of MtAnn1 mRNA during nodule development with in situ hybridization. Longitudinal sections (7 $\mu \mathrm{m})$ were hybridized with ${ }^{35} \mathrm{~S}$-labeled $M t A n n l$ antisense and sense riboprobes. Toluidine blue-stained sections are visualized in bright field images $(\mathbf{A}, \mathbf{D}$, and $\mathbf{F})$, where dark spots represent radioactive labeling. In the dark field images $(\mathbf{B}, \mathbf{E}, \mathbf{G}$, and $\mathbf{H})$, radioactive labeling appears as bright spots. Sections of young (6-dayold), isolated nodules of wild type Medicago truncatula hybridized with sense (C) and antisense (A, B, D, and E) MtAnn1 riboprobes. Remaining root tissues (cortex and epidermis) can be detected on the top of these young nodule sections. Section of a mature nodule (18-day-old) of wild-type M. truncatula hybridized with antisense MtAnn1 riboprobes (F and $\mathbf{G})$. Section of young, developing nodules from TR122 M. truncatula plants hybridized with antisense MtAnn1 riboprobes $(\mathbf{H})$. Symbols: star $=$ meristematic zone; arrows $=$ infection threads; asterisk $=$ nodule invasion zone II. Horizontal bars $=$ $80 \mu \mathrm{m}$. 
roots showed that MtAnnl transcripts accumulate at a high level and homogeneously in all nodule primordia cells (Fig. 4H, bottom).

\section{DISCUSSION}

In this paper we report the identification and characterization of a new gene from M. truncatula induced by $R$. meliloti Nod factors. This gene, designated MtAnnl, encodes a protein structurally homologous to the annexin family of calcium- and phospholipid-binding proteins. We show here that Nod factor induction of MtAnnl expression is related to the symbiotic process since MtAnnl is also expressed in $R$. melilotiinoculated roots and in $R$. meliloti-induced nodules. Thus the annexin-like MtAnnl gene constitutes a novel Nod factorinduced early nodulin gene from $M$. truncatula.

In situ hybridization of nodules has revealed that MtAnnl expression is associated with the distal part of invasion zone II, as is the case for the PsENOD12 (Scheres et al. 1990a, 1990b), MtENOD12 (Pichon et al. 1992) and MsENOD12A (Bauer et al. 1997) early nodulin genes characterized in indeterminate nodules. PsENOD12 is considered to be an infection-related marker gene since its expression is associated with the distal zone II containing actively growing infection threads (Scheres et al. 1990a, 1990b). MtENOD12 transcription is also maximal in cells containing infection threads, although it has been shown that expression is initiated within the narrow zone of cells, adjacent to the meristem and lacking infection threads, that is defined as the pre-infection zone (Pichon et al. 1992). MtAnnl expression is localized to the same region as MtENOD12 but the highest transcript levels are observed in the pre-infection zone rather than in the zone containing infection threads. This nodule pre-infection zone was defined on the basis of MtENOD12 expression in nodules (Pichon et al. 1992) and it has been suggested that the cells within this zone are being prepared for the subsequent infection process, by analogy with the early symbiotic expression of MtENOD12 in epidermal cells prior to Rhizobium infection of root hairs. Thus, MtAnn1 annexin is likely to play a role in this pre-infection process in nodules. It will now be necessary to determine the pattern of MtAnn1 expression in root tissues during early symbiotic stages.

To learn more about the expression of MtAnnl during nodulation, we made use of a variety of $R$. meliloti mutants. MtAnnl can be expressed independently of successful infection since induction of MtAnnl mRNA levels was observed in roots that were inoculated either with the nodFL $R$. meliloti mutant (absence of infection) or the exoA R. meliloti mutant (blocked in infection). These data also suggest that MtAnn1 is more likely to play a role in preparation for infection or nodule organogenesis, rather than in the infection process itself. Interestingly, the pattern of MtAnnl expression found in $R$. meliloti-induced nodules adjacent to meristematic cells is similarly found in exo nodules (data not shown) and for a MtAnnl homologue in spontaneous alfalfa NAR nodules (C. Grosjean, F. de Carvalho Niebel, and P. Gamas, unpublished data), suggesting that this sub-meristematic location of MtAnnl expression is not dependent on bacterial infection.

Sequence comparisons have shown that the protein encoded by the MtAnnl cDNA is a new member of the annexin protein family. Annexins constitute a family of calcium-dependent, phospholipid-binding proteins identified in many eukaryotic organisms (reviewed by Raynal and Pollard 1994; Kaetzel and Dedman 1995; Moss 1997). These proteins are amphipathic, soluble proteins, which in the presence of calcium can shift to a membrane-associated state. Annexins generally have a variable $\mathrm{N}$-terminal region and a conserved core region composed of four repeats (except for the animal class VI, containing eight repeats) of about 70 amino acids. The $\mathrm{N}$-terminal region of animal annexins can vary in length and in amino acid composition and is mostly associated with the specific properties of certain annexins (reviewed by Raynal and Pollard 1994; Moss 1997). It is interesting to note that all the reported fulllength plant sequences, including MtAnnl, have short $\mathrm{N}$ terminal sequences. Molecular phylogenetic analysis reveals at least 27 subfamilies of annexin proteins (Morgan and Fernandez 1997). The well-studied vertebrate annexins are classified within the 10 first subfamilies, sharing approximately $50 \%$ amino acid identity. The plant annexins have diverged significantly in comparison to animal annexins and fall into a separate group comprising at least 7 subfamilies represented in one or more plant species (Morgan and Fernandez 1997). Sequence comparison has shown that MtAnnl annexin is closer to an annexin from strawberry (Wilkinson et al. 1995) than to an annexin from the closely related species alfalfa (Pirck et al. 1994) (see Table 1), suggesting that MtAnnl and the alfalfa annexin belong to separate subfamilies. Given the high degree of sequence conservation observed for a number of genes between M. truncatula and alfalfa (Stanford et al. 1993; Crespi et al. 1994), it is likely that a homologue of MtAnn1 also exists in alfalfa. Indeed, RNA blot analysis at high stringency conditions with Mtannl cDNA as a probe demonstrated the induction of expression of an Mtann1 homologue in alfalfa NAR nodules (C. Grosjean, F. de Carvalho Niebel, and P. Gamas, data not shown).

Members of the annexin family can show different properties, although their actual cellular roles remain elusive (reviewed by Raynal and Pollard 1994; Moss 1997). In animal cells, annexins have been implicated in the transduction pathways of mitogenic signals, in membrane trafficking processes such as exocytosis, in interactions with cytoskeletal elements, or in the formation of voltage-dependent, ion-selective calcium channels (reviewed by Creutz 1992; Demange et al. 1994; Raynal and Pollard 1994). This wide variety of properties, together with varied intracellular localizations (associated with plasma or organelle membranes, cytoplasm, nuclei; see reviews of Gruenberg and Emans 1993; Raynal and Pollard 1994; Clark and Roux 1995) suggest that annexins are specialized for different cellular functions. In plants, annexins have also been reported to be associated with different cellular processes. Annexins purified from plant species such as tomato, maize, pea, cotton, and celery have different characteristics (reviewed by Clark and Roux 1995). For example, a celery annexin (Seals et al. 1994) was identified as a calciumdependent, vacuole-associated protein whereas a cotton annexin (Andrawis et al. 1993) was associated with the modulation of plasma membrane-located callose synthase activity. Although both tomato and maize annexins show ATPase activity, only the tomato annexins are able to interact with the cytoskeletal element actin (McClung et al. 1994; Calvert et al. 1996). Moreover, a role for annexins in the oxidative stress response has recently been proposed since an Arabidopsis 
thaliana annexin-encoding cDNA was able to complement an Escherichia coli mutant unable to grow in the presence of high concentrations of $\mathrm{H}_{2} \mathrm{O}_{2}$ (Gidrol et al. 1996). Finally, cDNA sequences to annexin genes showing enhanced expression during fruit maturation have been identified both in strawberry (Wilkinson et al. 1995) and in bell pepper (Proust et al. 1996). Further analysis would help to elucidate which of the reported properties of annexins are common or specific to different members.

The identification of a novel Nod-factor-induced early nodulin gene coding for an annexin opens new perspectives in relation to the molecular events occurring at early symbiotic stages. In particular, the specific Nod factor induction of the MtAnnl gene raises the intriguing question of whether the MtAnn1 protein could play a role in the Nod factor signaling pathway(s) that lead(s) to the induction of the early symbiotic responses. At this stage, several of the potential roles attributed to annexins could be envisaged for the MtAnn1 annexin during the symbiotic process, and certain of the recently reported Nod-factor-induced cellular responses could be related to MtAnn1 protein function. For example, Ehrhardt et al. (1996) have recently reported that periodic calcium spiking can be elicited in alfalfa root hairs in response to specific $R$. meliloti Nod factors, suggesting that calcium may be a second messenger in Nod factor signaling. In this context, annexins are calcium-binding proteins and many of their functions are mediated by or dependent on the presence of calcium ions. We can also speculate that MtAnn1 function may be related to the changes occurring in the cellular cytoskeleton during the nodulation process, since certain annexin proteins can interact in a calcium-dependent manner with cytoskeletal elements such as actin (Thiel et al. 1992; Calvert et al. 1996). Changes in the cytoskeletal network associated with different symbiotic events such as cortical cell activation and root hair deformation have been reported (Bakhuisen 1988; Allen et al. 1994). More detailed analyses on the spatial and temporal expression patterns of MtAnnl during early symbiotic stages, as well as the analysis of the biochemical properties and sub-cellular location of the MtAnn1 protein, should help to elucidate the cellular role of MtAnn1 in the symbiotic process.

\section{MATERIALS AND METHODS}

\section{Plant treatments.}

Both wild- type and the supernodulating mutant line TR122 (Sagan et al. 1995) of Medicago truncatula cv. Jemalong (genotype J5) were used in this work. For nodulation studies, plants were grown either aeroponically or in pouches as described in Gamas et al. (1996). Bacterial inoculations were performed on roots of nitrogen-starved, 1-month-old, aeroponically grown plants, or 8-day-old pouch-grown plants. The bacterial strains used were as follows: Rhizobium meliloti RCR 2011 (GMI6526; Ardourel et al. 1994), R. meliloti RCR 2011 nodA::Tn5 \#2208 (GMI5382; Debéllé et al. 1986), $R$. meliloti RCR2021 nodH::Tn5 \#2313 (GMI6527; Faucher et al. 1989), R. meliloti RCR2021 nodFL:: (nodF) 13 nodL::Tn5 (GMI6629; Ardourel et al. 1994), and R. meliloti 1021 exoA32::Tn5 (provided by J. Leigh, Washington University, Seattle). Inoculated roots or isolated nodules were harvested at different times, frozen immediately in liquid nitrogen, and stored at $-70^{\circ} \mathrm{C}$.
Nod factor treatments were performed on 8-day-old pouchgrown plants by adding growth medium only (control) or growth medium supplemented with $10^{-7} \mathrm{M}$ NodRm factors to the plant roots. Whole root systems were harvested at different times, frozen in liquid nitrogen, and stored at $-70^{\circ} \mathrm{C}$. The NodRm factors are as described in Gamas et al. (1996). For pathogenesis studies, leaves of 2-week-old, pouch-grown plants were infiltrated with bacterial suspensions containing approximately $10^{8} \mathrm{CFU} / \mathrm{ml}$.

The bacteria used were the incompatible bacteria Pseudomonas syringae pv. pisi (D. Roby, this laboratory) and the compatible bacteria Xanthomonas campestris pv. alfalfae (provided by CFBP, French Collection of Phythopathogenic Bacteria, INRA Station de Phytobactériologie, Beaucouzé, France). Leaf tissues were harvested after different times postinoculation: $3,6,23$, and $48 \mathrm{~h}$ for the incompatible interaction, and 6,23 , and $48 \mathrm{~h}$ for the compatible bacteria. To evaluate possible wound induction of MtAnn1, M. truncatula leaves were cut in strips about $1 \mathrm{~mm}$ wide and incubated in MS medium (Murashige and Skoog 1962). Uncut control leaves were also incubated in MS medium. Leaf tissues were harvested after incubation for $30 \mathrm{~s}$ and 1, 2, 4, and $24 \mathrm{~h}$ on MS medium.

$M$. truncatula plants grown aeroponically were used for the isolation of total RNA from root, leaf, flower, and stem tissues.

\section{RT-PCR differential display.}

Reverse transcription (RT)-PCR differential display was performed essentially as described by Liang et al. (1994) with certain modifications. Total RNA was extracted from control roots and roots treated with NodRm factors for 2, 24, and 48 h. To eliminate contaminating genomic DNA, DNaseI (Promega, Madison, WI), treatment of RNA samples was carried out as described by Liang et al. (1994). The concentration and integrity of the RNA samples was evaluated by spectrophotometric analysis and gel electrophoresis. DNA-free total RNA $(0.2 \mu \mathrm{g})$ was used in first-strand cDNA synthesis reactions primed with $10 \mu \mathrm{M}$ oligo $\left(\mathrm{dT}_{11}\right)$ primers with two anchored bases: $\mathrm{dT}_{11} \mathrm{CC}, \mathrm{dT}_{11} \mathrm{CG}, \mathrm{dT}_{11} \mathrm{AC}$, or $\mathrm{dT}_{11} \mathrm{GG}$. Reverse transcription was carried out following the Superscript RT RNase $\mathrm{H}^{-}$protocol (Gibco BRL, Life Technologies, Gaithersburg, MD). After heat inactivation, $10 \%$ of the cDNA was amplified by PCR with combinations of anchored oligo dT primers and 10-mer primers (OP: A-08, B-11, J-09, J-13, K04, K-07, K-12, L-17, M-14, M-15, N-09, or N-12, Operon Technologies, Alameda, CA). Fifty-one, 31, and 20 primer combinations were used for, respectively, the 2-, 24-, and 48-h samples. PCR reactions were performed as described by Liang et al. (1994). Six microliters of each PCR reaction was denatured and analyzed on $6 \%$ denaturing polyacrylamide gels. PCR bands that were differential in three independent RTPCRs were excised from gels and re-amplified by PCR as described by Liang et al. (1994). The re-amplified, blunt-ended cDNA fragments were cloned in a pUC18 vector with the Sure Clone Ligation Kit from Pharmacia Biotech (Uppsala, Sweden). Positive bacterial colonies with the expected insert sizes were selected by PCR amplification with primers to the vector polylinker sequences.

\section{RNA gel blot analysis.}

Total RNA was extracted from nodule, root, leaf, stem, and floral tissues as described by Jackson and Larkins (1976). 
When indicated, polyA ${ }^{+}$RNA was extracted from total RNA preparations with magnetic beads (Dynabeads oligo dT25 from Dynal, Oslo, Norway). Total RNA $(10 \mu \mathrm{g})$ or $120 \mathrm{ng}$ of polyA $^{+}$RNA was electrophoresed in a $1.5 \%$ agaroseformaldehyde gel and blotted on Nytran-plus membranes (Schleicher \& Schuell, Dassel, Germany) according to Sambrook et al. (1989). To verify RNA quality and quantity, ethidium bromide $(0.25 \mu \mathrm{g}$ per RNA sample) was added to samples prior to gel electrophoresis, and the RNA samples were photographed after blotting. Plasmids containing MtAnn1 sequences cloned in the pBluescript II vector (Stratagene, La Jolla, CA) were used to generate $\alpha^{32} \mathrm{P}$-labeled riboprobes with the Promega transcription kit. To detect EF-I $\alpha$ transcripts, radioactive DNA probes were generated from an A. thaliana EF-I $\alpha$ gene (Axelos et al. 1989), using the Ready to Go labeling kit (Pharmacia). Hybridization and washing conditions were essentially performed as described in Gamas et al. (1996).

\section{DNA sequencing and sequence analysis.}

Plasmid DNA prepared with the Wizard miniprep kit (Promega) was sequenced on both strands by using the double-stranded dideoxy chain termination method with Sequenase enzyme (Amersham International, Les Ulis, France). Sequence data were analyzed with the University of Wisconsin Computer group (GCG) software. The EMBL accession number for the MtAnn1 cDNA sequence is Y15036.

\section{cDNA library screening.}

The MtAnnl cDNA clone was isolated from a directional Lambda ZAP II (Stratagene) cDNA library prepared from RNA isolated from M. truncatula roots 6, 24, and $48 \mathrm{~h}$ after inoculation with $R$. meliloti (Szybiak-Strozycka et al. 1995). About 270,000 plaques plated onto $15-\mathrm{cm}$ plates (approximately 46,000 plaques per plate) were transferred onto replica reinforced nitrocellulose membranes (Optitran BA-S 85, Schleicher \& Schuell) that were then hybridized with ${ }^{32} \mathrm{P}$-labeled $d d A$ DNA probes. Hybridization and washing conditions were the same as for RNA blot hybridizations except that the hybridization temperature was $42^{\circ} \mathrm{C}$. Positive phage plaques were directly used for PCR amplification with the 5'M13-reverse primer to Lambda ZAP sequences, and the $3^{\prime} \mathrm{Fc} 2$ primer (5'TCCCCAAGAGAGTGAGAAG3') to the $d d A$ sequences. Phage plates that generated PCR products of the expected size for the entire $d d A$ cDNA sequence were selected for phage purification and DNA in vivo excision following manufacturer's instructions (Stratagene).

\section{In situ hybridization.}

In situ hybridizations were performed with $7-\mu \mathrm{m}$ sections of nodules isolated from pouch-grown plants, as described by van de Wiel et al. (1990) except that slides were exposed for 3 weeks with Amersham LM1 emulsion (Amersham). MtAnn1 sense and antisense riboprobes were synthesized following the Promega transcription kit protocol and were labeled with 50 $\mu \mathrm{Ci}$ of ${ }^{35} \mathrm{~S}-\mathrm{UTP}(1,500 \mathrm{Ci} / \mathrm{mmol})$. Probes were partially degraded to a length of approximately 150 bases before hybridization with tissue sections. Hybridizations were performed in a volume of $100 \mu \mathrm{l}$ per slide containing $5 \times 10^{6} \mathrm{cpm}$ of probe (approximately $3 \times 10^{6} \mathrm{cpm} / \mu \mathrm{l}$ ).

\section{ACKNOWLEDGMENTS}

We thank David Barker for stimulating discussions, David Barker, Andreas Niebel, and Vanessa Vernoud for valuable comments on the manuscript, René Mathis and Françoise de Billy for helpful suggestions and discussions concerning the in situ hybridization technique, and Georges Truchet for helpful comments on the in situ hybridization results. This work was supported by the European Community Human Capital and Mobility Program (network CHRX, CT940656). F. d. C. N. is indebted to the European Community for a post-doctoral fellowship.

\section{LITERATURE CITED}

Allen, N. S., Bennett, M. N., Cox, D. N., Shipley, A., Ehrhardt, D. W., and Long S. R. 1994. Effects of Nod factors on alfalfa root hair $\mathrm{Ca}^{++}$ and $\mathrm{H}^{+}$currents and on cytoskeletal behavior. Pages 107-114 in: Advances in Molecular Genetics of Plant-Microbe Interactions, Vol. 3. M. G. Daniels, J. A. Downie, and A. E. Osborne, eds. Kluwer Academic Pub., Dordrecht, The Netherlands.

Altschul, S. F., Gish, W., Miller, W., Myers, E. W., and Lipman, D. 1990. Basic local alignment search tool. J. Mol. Biol. 215:403-410.

Andrawis, A., Solomon, M., and Delmer, D. P. 1993. Cotton fiber annexins: A potential role in the regulation of callose synthase. Plant $\mathrm{J}$. 3:763-772.

Ardourel, M., Demont, N., Debellé, F., Maillet, F., de Billy, F., Promé, J. C., Dénarié, J., and Truchet, G. 1994. Rhizobium meliloti lipooligosaccharide nodulation factors: Different structural requirements for bacterial entry into target root hair cells and induction of plant symbiotic developmental responses. Plant Cell 6:1357-1374.

Axelos, M., Bardet, C., Liboz, T., Le Van Thai, A., Curie, C., and Lescure, B. 1989. The gene family encoding the Arabidopsis thaliana elongation factor $E F-1 \alpha$ : Molecular cloning, characterization and expression. Mol. Gen. Genet. 219:106-112.

Bakhuisen, S. 1988. The plant cytoskeleton in the Rhizobium-legume symbiosis. Ph.D. diss. Leiden University, Leiden, The Netherlands.

Bauchrowitz, M. A., Barker, D. G., and Truchet, G. 1996. Lectin genes are expressed throughout root nodule development and during nitrogen-fixation in the Rhizobium-Medicago symbiosis. Plant J. 9:31-43.

Bauer, P., Poirier, S., Ratet, P., and Kondorosi, A. 1997. MsEnod12A expression is linked to meristematic activity during development of indeterminate and determinate nodules and roots. Mol. Plant-Microbe Interact. 10:39-49.

Bauer, P., Ratet, P., Crespi, M. D., Schultze, M., and Kondorosi, A. 1996. Nod factors and cytokinins induce similar cortical cell division, amyloplast deposition and MsEnod $12 \mathrm{~A}$ expression patterns in alfalfa roots. Plant J. 10:91-105.

Calvert, C., Gant, S. J., and Bowles, D. J. 1996. Tomato annexins p34 and p35 bind to F-actin and display nucleotide phosphodiesterase activity inhibited by phospholipid binding. Plant Cell 8:333-342.

Clark, G. B., and Roux, S. J. 1995. Annexins of plant cells. Plant Physiol. 109:1133-1139.

Coba de la Pena, T., Frugier, F., McKhann, H. I., Bauer, P., Brown, S., Kondorosi, A., and Crespi, M. D. 1997. A carbonic anhydrase gene is induced in the nodule primordium and its cell-specific expression is controlled by the presence of Rhizobium during development. Plant J. 11:407-420.

Cook, D., Dreyer, D., Bonnet, D., Howell, M., Nony, E., and VandenBosch, K. 1995. Transient induction of a peroxydase gene in Medicago truncatula precedes infection by Rhizobium meliloti. Plant Cell 7:43-55.

Crespi, M. D., Jurkevitch, E., Poiret, M., d'Aubenton-Carafa, Y., Petrovics, G., Kondorosi, E., and Kondorosi, A. 1994. Enod40, a gene expressed during nodule organogenesis, codes for a non-translatable RNA involved in plant growth. EMBO J. 13:5099-5112.

Creutz, C. E. 1992. The annexins and exocytosis. Science 258:924-931.

Debellé, F., Rosenberg, C., Vasse, J., Maillet, F., Martinez, E., Dénarié, J., and Truchet, G. 1986. Assignment of symbiotic developmental phenotypes to common and specific (nod) genetic loci of Rhizobium meliloti. J. Bacteriol. 168:1075-1086.

Demange, P., Voges, D., Benz, J., Liemann, S., Göttig, P., Berendes, S. Burger, A., and Huber, S. 1994. Annexin V: The key to understanding ion selectivity and voltage regulation? Trends Biochem. Sci. 19:272276. 
Dénarié, J., Debellé, F., and Promé, J.-C. 1996. Rhizobium lipochitooligosaccharide nodulation factors: Signaling molecules mediating recognition and morphogenesis. Annu. Rev. Biochem. 65:503535 .

Ehrhardt, D. W., Wais, S., and Long, S. R. 1996. Calcium spiking in plant root hairs responding to Rhizobium nodulation signals. Cell 85: 673-681.

Faucher, C., Camut, S., Dénarié, J., and Truchet, G. 1989. The nodH and nodQ host range genes of Rhizobium meliloti behave as avirulence genes in S. leguminosarum bv. viciae and determine changes in the production of plant-specific extracellular signals. Mol. Plant-Microbe Interact. 2:291-300.

Gamas, P., de Billy, F., and Truchet, G. 1998. Symbiosis-specific expression of two Medicago truncatula nodulin genes, MtN1 and MtN13, encoding products homologous to plant defense proteins. Mol. PlantMicrobe Interact. 11:393-403.

Gamas, P., de Carvalho Niebel, F., Lescure, N., and Cullimore, J. V. 1996. Use of a subtractive hybridization approach to identify new Medicago truncatula genes induced during root nodule development. Mol. Plant-Microbe Interact. 9:233-242.

Gidrol, X., Sabelli, P. A., Fern, Y. S., and Kush, A. K. 1996. Annexinlike protein from Arabidopsis thaliana rescues $\Lambda$ oxy R mutant of Escherichia coli from $\mathrm{H}_{2} \mathrm{O}_{2}$ stress. Proc. Natl. Acad. Sci. USA 93:1126811273.

Goormachtig, S., Valerio-Lepiniec, M., Szczyglowski, K., Van Montagu, M., Holsters, M., and de Bruijn, F. J. 1995. Use of differential display to identify novel Sesbania rostrata genes enhanced by Azorhizobium caulinodans infection. Mol. Plant-Microbe Interact. 8:816-824.

Gruenberg, J., and Emans, N. 1993. Annexins in membrane traffic. Trends Cell Biol. 3:224-227.

Heidstra, R., and Bisseling, T. 1996. Nod-factor induced host responses and mechanisms of Nod factor perception. New Phytol. 133:25-43.

Heidstra, R., Nilsen, G., Martinez-Abarca, F., van Kammen, A., and Bisseling, T. 1997. Nod factor-induced expression of leghemoglobin to study the mechanism of $\mathrm{NH}_{4} \mathrm{NO}_{3}$ inhibition on root hair deformation. Mol. Plant-Microbe Interact. 10:215-220.

Horvath, B., Heidstra, R., Lados, M., Moerman, M., Spaink, H. P., Promé, J.-C., van Kammen, A., and Bisseling, T. 1993. Lipo-oligosaccharide of Rhizobium induce infection-related early nodulin gene expression in pea root hairs. Plant J. 4:727-733.

Jackson, A. D., and Larkins, B. A. 1976. Influence of ionic strength, pH, and chelation of divalent metals on isolation of polyribosomes from tobacco leaves. Plant Physiol. 57:5-10.

Journet, E. P., Pichon, M., Dedieu, A., de Billy, F., Truchet, G., and Barker, D. G. 1994. Rhizobium meliloti Nod factors elicit cell-specific transcription of the ENOD12 gene in transgenic alfalfa. Plant J. 6:241249.

Kaetzel, M. A., and Dedman, J. S. 1995. Annexins: novel $\mathrm{Ca}^{2+}$ dependent regulators of membrane function. NIPS 10:171-176.

Liang, P., Averboukh, L., and Pardee, A. B. 1994. Method of differential display. Pages 3-16 in: Methods in Molecular Genetics, Vol. 5. Academic Press, San Diego, CA.

Long, S. R. 1996. Rhizobium symbiosis: Nod factors in perspective. Plant Cell 8:1885-1898.

Matvienko, M., Van De Sande, K., Yang, M.-C., Van Kammen, A., and Bisseling, T. 1994. Comparison of soybean and pea ENOD40 cDNA clones representing genes expressed during both early and late stages of nodule development. Plant Mol. Biol. 26:487-493.

McClung, A. D., Carrol, A. D., and Battey, N. H. 1994. Identification and characterization of ATPase activity associated with maize (Zea mays) annexins. Biochem. J. 303:709-712.

Minami, E., Kouchi, H., Cohn, J. S., Ogawa, T., and Stacey, G. 1996. Expression of the early nodulin, ENOD40, in soybean roots in response to various lipo-chitin signal molecules. Plant J. 10:23-32.

Morgan, S. O., and Fernandez, M. P. 1997. Distinct annexin subfamilies in plants and protists diverged prior to animal annexins and from a common ancestor. J. Mol. Evol. 44:178-188.

Moss, S. E. 1997. Annexins. Trends Cell Biol. 7:87-89.

Murashige, T., and Skoog, F. 1962. A revised medium for rapid growth and bioassays with tobacco tissue cultures. Physiol. Plant. 15:473497.

Mylona, P., Pawlowski, K., and Bisseling, T. 1995. Symbiotic nitrogen fixation. Plant Cell 7:869-885.

Nakai, K., and Kanehisa, M. 1992. A knowledge base for predicting protein localization sites in eukaryotic cells. Genomics 14:897-911.

Papadopoulou, K., Roussis, A., and Katinakis, P. 1996. Phaseolus ENOD4O is involved in symbiotic and non-symbiotic organogenetic processes: expression during nodule and lateral root development. Plant Mol. Biol. 30:403-417.

Pichon, M., Journet, E. P., Dedieu, A., de Billy, F., Truchet, G., and Barker, D. G. 1992. Rhizobium meliloti elicits transient expression of the early nodulin gene ENOD12 in the differentiating root epidermis of transgenic alfalfa. Plant Cell 4:199-1211.

Pirck, M., Hirt, H., and Heberle-Bors, E. 1994. The cDNA sequence encoding an annexin from Medicago sativa. Plant Physiol. 104:14631464.

Proust, J., Houlné, G., Schantz, M.-L., and Schantz, S. 1996. Characterization and gene expression of an annexin during fruit development in Capsicum annuum. FEBS Lett. 383:208-212.

Raynal, P., and Pollard, H. B. 1994. Annexins: The problem of assessing the biological role for a gene family of multifunctional calcium- and phospholipid-binding proteins. Biochem. Biophys. Acta 1197:63-93.

Sagan, M., Morandi, D., Tarenghi, E., and Duc, G. 1995. Selection of nodulation and mycorrhizal mutants in the model plant Medicago truncatula (Gaertn.) after $\gamma$-ray mutagenesis. Plant Sci. 111:63-71.

Sambrook, J., Fritsch, E. F., and Maniatis, T. A. 1989. Molecular Cloning: A Laboratory Manual. 2nd ed. Cold Spring Harbor Laboratory, Cold Spring Harbor, NY.

Scheres, B., Van de Wiel, C., Zalensky, A., Horvath, B., Spaink, H., Van Eck, H., Zwartkhuis, F., Wolters, A.-M., Gloudemans, T., Van Kammen, A., and Bisseling, T. 1990a. The ENOD12 gene product is involved in the infection process during the pea-Rhizobium interaction. Cell 60:281-294.

Scheres, B., van Engelen, F., van der Knaap, E., van de Wiel, C., van Kammen, A., and Bisseling, T. 1990b. Sequential induction of nodulin gene expression in the developing pea nodule. Plant Cell 2: 687-700.

Schultze, M., and Kondorosi, A. 1996. The role of lipooligosaccharides in root nodule organogenesis and plant cell growth. Cur. Opin. Genet. Dev. 6:631-638.

Seals, D. F., Parrish, M. L., and Randall, S. K. 1994. A 42-kilodalton annexin-like protein is associated with plant vacuoles. Plant Physiol. 106:1403-1412.

Spaink, H. P. 1996. Regulation of plant morphogenesis by lipo-chitin oligosaccharides. Crit. Rev. Plant Sci. 15:559-582.

Stanford, A., Larsen, K., Barker, D. G., and Cullimore, J. V. 1993. Differential expression within the glutamine synthetase gene family of the model legume Medicago truncatula. Plant Physiol. 103:73-81.

Szybiak-Strozycka, U., Lescure N., Cullimore, J. V., and Gamas, P. 1995. A cDNA encoding a PR-1 like protein in the model legume Medicago truncatula. Plant Physiol. 107:273-274

Thiel, C., Osborn, M., and Gerke, V. 1992. The tight association of the tyrosine kinase substrate annexin II with the submembranous cytoskeleton depends on intact p11- and Ca2+-binding sites. J. Cell Sci. 103:733-742

Thompson, J. D., Higgins, D. J., and Gibson, T. J. 1994. CLUSTAL W: Improving the sensitivity of progressive multiple sequence alignment through sequence weighting, position-specific gap penalties and weight matrix choice. Nucleic Acids Res. 22:4673-4680.

van de Wiel, C., Scheres, B., Franssen, H., van Lierop, M.-J., van Lammeren, A., van Kammen, A., and Bisseling, T. 1990. The early nodulin transcript ENOD2 is located in the nodule parenchyma (inner cortex) of pea and soybean root nodules. EMBO J. 9:1-7.

Vijn, I., Martinez-Abarca, F., Yang, W. C, das Neves, L., van Brussel, A., van Kammen, A., and Bisseling, T. 1995. Early nodulin gene expression during Nod factor-induced processes in Vicia sativa. Plant J. 8:111-119.

Wilkinson, J. Q., Lanahan, M. B., Conner, T. W., and Klee, H. J. 1995 Identification of mRNAs with enhanced expression in ripening strawberry fruit using polymerase chain reaction differential display. Plant Mol. Biol. 27:1097-1108.

Yang, C., Signer, E. R., and Hirsch, A. M. 1992. Nodules initiated by Rhizobium meliloti exopolysaccharide mutants lack a discrete, persistent nodule meristem. Plant Physiol. 98:143-151. 